1 Universidade do Estado do Rio de Janeiro (Uerj), Instituto de Medicina Social (IMS) - Rio de Janeiro (RJ), Brasil. taniafranca@ims.uerj.br

2 Universidade Federal de Minas Gerais (UFMG),

Departamento de Medicina Preventiva e Social - Belo Horizonte (MG), Brasil.

soraya@nescon.medicina. ufmg.br

${ }^{3}$ Fundação Oswaldo Cruz (Fiocruz). Instituto Aggeu Magalhães - Recife (PE) Brasil.

kmedeiros@cpqam.fiocruz.br

4 Universidade Federal da Bahia (UFBA), Instituto de Saúde Coletiva (ISC) Salvador (BA), Brasil.

isabela@ufba.br

5 Universidade Federal do Espírito Santo (Ufes), Programa de Pós-

Graduação em Saúde

Coletiva - Vitória (ES),

Brasil.

anacpgarcia@hotmail.com

\section{Limites e possibilidades das Comissões Permanentes de Integração Ensino-Serviço: percepções dos gestores}

\author{
Limits and possibilities of the Permanent Committees of Education- \\ Service Integration: managers' perceptions
}

Tania França1, Soraya Almeida Belisário ${ }^{2}$, Katia Rejane Medeiros ${ }^{\mathbf{3}}$, Isabela Cardoso de Matos Pinto ${ }^{4}$, Ana Claudia Pinheiro Garcia 5

RESUMO Este é um estudo qualitativo desenvolvido com gestores da saúde dos quadros estadual e nacional que analisou as dificuldades na implementação das Comissões Permanentes de Integração Ensino-Serviço por meio de entrevistas. Observaram-se dificuldades relacionadas com infraestrutura, gestão de processos administrativos na contratação e execução das ações de Educação Permanente, práticas pedagógicas inovadoras e incipiência do controle social. Dentre os desafios estão a sustentação e articulação de parcerias institucionais entre serviço e ensino, educação e trabalho, numa perspectiva baseada no diálogo e no compartilhamento; o monitoramento contínuo do impacto das ações na qualificação dos serviços; além de maior desenvolvimento na pesquisa.

PALAVRAS-CHAVE Recursos humanos em saúde. Avaliação em saúde. Políticas públicas. Educação em saúde. Sistema Único de Saúde.

ABSTRACT This is a qualitative study developed with health managers from state and national levels, who examined the implementation difficulties of Permanent Committees of EducationService Integration by means of interviews. We observed the existence of constraints regarding infrastructure, administrative procedures management involving procurement and implementation of permanent education actions, innovative pedagogical practices, and social control shortcomings. Among the challenges we can note the support and coordination of institutional partnerships between service and teaching, education and work, based on a dialogued and shared perspective; the ongoing monitoring of actions' impact on services qualification; in addition to further research development.

KEYWORDS Health manpower. Health evaluation. Public policies. Health education. Unified Health System. 


\section{Introdução}

As dificuldades na implantação de novas práticas na área da gestão governamental, inclusive na saúde, têm estimulado questionamentos acerca dos fatores que influenciam o processo de decisão, formulação e implantação das políticas públicas. Em função disso, alguns estudos têm gerado uma série de modelos explicativos do processo de decisão, elaboração, implantação e avaliação das ações governamentais para explicar e compreender o processo decisório no âmbito das políticas públicas, como estas são formuladas pelo Estado e como são definidas as responsabilidades por sua implantação nos diversos níveis de governo (PINTO ET AL., 2016). A fase de implementação tem sido considerada o momento crucial do ciclo de uma política pública, onde as propostas se materializam em ação institucionalizada por meio da atuação dos responsáveis por operacionalizar decisões. Nesse processo, vários fatores podem interferir para o sucesso ou fracasso de um projeto, visto que envolvem diferentes atores políticos, instâncias decisórias e ações administrativas necessárias à sua operacionalização. Nesse sentido, a negociação é fundamental, para definir e sustentar pactos necessários à potencialidade da política a ser colocada em prática (PINTO ET AL., 2016).

A Educação Permanente na Saúde (EPS) tornou-se a estratégia do Sistema Único de Saúde (SUS) para a formação e o desenvolvimento de trabalhadores da saúde, e tem como objeto a transformação do processo de trabalho, orientado para a melhoria da qualidade dos serviços e para a equidade no cuidado e no acesso aos serviços (LIMA; ALBUQUERQUE; WENCESLAU, 2014; MACHADO ET AL., 2015).

A Portaria GM/MS n ${ }^{\circ}$ 1.996/07 definiu, em seu art. $2^{\circ}$, que a condução regional da Política Nacional de Educação Permanente em Saúde (PNEPS) ocorreria por meio de Colegiados de Gestão Regional (CGRs), definidos como instâncias de pacto permanente e cogestão solidária e cooperativa, formados pelos gestores municipais de saúde de uma determinada região e por representantes do gestor estadual (BRASIL, 2007). Para a condução da política, a portaria indicou como estratégia a instalação das Comissões Permanentes de Integração Ensino-Serviço (Cies), definidas como instâncias intersetoriais e interinstitucionais permanentes, de composição plural, que participam da formulação, condução e desenvolvimento da PNEPS (VIANA, 2007). As alterações introduzidas pela Portaria $n^{\circ}$ 1996/07 no nível estadual ratificam o papel de protagonista assumido pelas Secretarias de Estado da Saúde (SESs) na condução da PNEPS, responsabilizando-as pelo planejamento da formação dos trabalhadores do SUS em seu âmbito de gestão por meio das Comissões Inter gestoras Regionais (CIRs) (KEHRIG; SOUZA; SCATEN, 2015; SANDRI ET AL., 2016). Estas passariam, então, a assumir a condução regional da política, operando como instância deliberativa, responsável pela elaboração dos planos regionais de Educação Permanente (EP), pactos e definição de projetos a serem implantados no campo da formação e qualificação da força de trabalho para a saúde.

Este artigo objetivou, a partir da perspectiva dos atores envolvidos, analisar as dificuldades no processo de implantação das Cies, bem como as estratégias utilizadas para sua superação. Os elementos aqui apresentados integram a pesquisa 'Análise da Política de Educação Permanente implantada pelas Secretarias Estaduais de Saúde', desenvolvida em âmbito nacional.

\section{Métodos}

Trata-se de estudo multicêntrico, de abordagem qualitativa, onde as SESs e as Cies atuaram como cenário, e, como informantes-chave, os gestores ou responsáveis pela condução da política de EPS nas SESs. Para a coleta dos dados, disponibilizou-se questionário em meio on-line, além de entrevista semiestruturada dirigida aos coordenadores 
das Cies e ao coordenador nacional da PNEPS/SUS. Cabe destacar que as análises aqui apresentadas se referem apenas às entrevistas semiestruturadas. As oito entrevistas foram conduzidas por quatro pesquisadores, a partir de um roteiro previamente elaborado, sendo todas gravadas e posteriormente transcritas.

Selecionaram-se, por sorteio, sete Cies, sendo uma da região Sul, uma do Sudeste, uma do Centro-Oeste, duas da região Norte e duas da Nordeste. As entrevistas foram realizadas entre agosto e novembro de 2015.

Após sua transcrição na íntegra, as entrevistas foram submetidas à análise de conteúdo temático de Bardin (2008), operacionalizada em três etapas: pré-análise, que consistiu na organização do material a ser analisado mediante leitura e demarcação dos trechos a serem trabalhados; codificação, classificação e categorização do material; e interpretação dos resultados, do qual emergiram, então, as categorias, dificuldades, estratégias para o enfrentamento das dificuldades, desafios e perspectivas.

A pesquisa foi aprovada pelo Comitê de Ética em Pesquisa do Instituto de Medicina Social da Universidade do Estado do Rio de Janeiro, sob o registro CEP $\mathrm{n}^{0}$ 695267, de 2014, e todos os participantes assinaram o Termo de Consentimento Livre e Esclarecido (TCLE). Para preservar o anonimato, os entrevistados foram identificados pela letra $\mathrm{E} \mathrm{e}$ numerados de 1 a 8 .

\section{Resultados e discussão}

\section{Dificuldades na implantação das Cies}

Foram diversas e de diferentes naturezas as dificuldades reclamadas pelos entrevistados, as quais integraram um rol de questões tanto no que se refere a processos internos e inerentes a cada estado como relativas a questões de âmbito mais geral.
Assim, enumeram-se como dificuldades a baixa prioridade dada pelos gestores estaduais e municipais à EP; entraves burocráticos, em forma geral; dificuldade dos estados e municípios na execução dos recursos e restrições legais para sua utilização; ausência de corpo docente nas escolas técnicas, dentre outras.

[...] os lugares, seja município, seja estado, que queriam fazer alguma ação de Educação Permanente eles acabam preferindo usar recurso do tesouro deles que utilizar o recurso da Educação Permanente porque era um recurso repassado num formato de tal forma que dificultava a execução por ter um conjunto de regras [...] tem estado que tem dificuldade de executar, por exemplo, pagamento de hora-aula. Tem lei que proíbe pagar servidor que é um modelo muito utilizado pra repor as escolas técnicas que não tem corpo docente próprio etc. (E8).

Esses achados corroboram estudos anteriores, como os de Lima, Albuquerque e Wenceslau (2014), que identificaram a baixa priorização da EPS pela gestão no município de Recife. $\mathrm{O}$ aperfeiçoamento dos processos administrativos e marcos legais, que torna estados e municípios aptos a viabilizar a contratação e execução das ações de EP, é referido por D’Avila, Assis e Melo (2014). É preciso aperfeiçoar os processos administrativos e os marcos legais de estados e municípios para viabilizar a contratação e execução das ações de EP (STROSCHEIN; ZOCHE, 2011).

Para outro entrevistado, as dificuldades são a grande extensão territorial do seu estado, com municípios distantes e de difícil acesso; o difícil processo de regionalização do estado e de reorganização da Comissão Interinstitucional Bipartite (CIB), que complicaram a implantação das Cies; o acesso ao Secretário de Saúde; a dificuldade da gestão municipal em assimilar a EP como uma política pública de saúde e a grande rotatividade dos gestores municipais de saúde (FRANÇA ET AL., 2016; LIMA; ALBUQUERQUE; WENCESLAU, 2014). 
A pouca clareza dos membros da Cies sobre o que ela é e faz, bem como sua baixa participação, envolvimento e compromisso foram relatados por outro entrevistado. Essa evidência também foi captada por Ferraz et al. (2013), que afirmaram que as Cies precisam conhecer o processo de gestão, organização e estruturação da PNEPS dos seus respectivos territórios de abrangência.

Eu acho que a principal dificuldade hoje não é o financiamento só não. [...] é mais a capacitação mesmo, é a questão do entendimento, da participação dos membros [...] [...] saber o que tem que fazer, de saber o que é Cies. [...]. Eu acho que isso que está faltando mais na Cies hoje pra ela realmente ser atuante. [...] você conta quem tem esse compromisso e de quem sabe o que é Cies. (E3).

Outras dificuldades relatadas foram a baixa capacidade organizativa; a oferta de eventos pulverizados, fragmentados, sem conexão entre si e de baixa carga horária, muitas vezes decorrentes das necessidades de outros setores; e a baixíssima presença da EP nas pautas da CIB, pautas estas, dominadas pela discussão assistencial. Sarreta (2009) adverte que o grande desafio é superar a educação como um elemento funcional e ser capaz de ir além dos cursos e treinamentos isolados e voltados para problemas imediatos dos serviços. Nas práticas de saúde, são indispensáveis as propostas educativas reiterativas e tecnicistas, com ênfase em treinamentos, capacitações e cursos em áreas específicas, embora seja fundamental transcender a fragmentação e a descontinuidade (SILVA ET AL., 2013).

A pouca prioridade dada à EP pela gestão foi ressaltada como um paradoxo, uma vez que é comum os gestores se referirem à importância e à necessidade da EP, embora não aloquem recursos e muito menos a tratem como prioridade.

Para Campos (2006), há, entre as autoridades do poder executivo, uma visão muito instrumental e imediatista das políticas de formação, ligadas mais à perspectiva eleitoral e menos a uma preocupação estrutural e reflexiva para a formação.

A não compreensão pelo Conselho Nacional de Saúde do que seja a Cies e o desconhecimento do que seja a política de EP também foram lembrados por outro depoente. No que se refere à gestão, outro entrevistado relatou que esta criou várias dificuldades ao processo.

[...] aí a gente começou a ter dificuldades, a gente ter um plano e não conseguir botar em prática, sempre tinha uma desculpa [...] Então sempre tinha um obstáculo e sempre jogando responsabilidade para os membros da Cies, né? Como se a gestão não fizesse parte do processo. (E5).

Para ele, há uma grande expectativa em relação à Cies como a executora da política. Contudo, avalia que a Cies tem dificuldade em atendê-la, devido à ausência de instrumento de gestão.

Então fica uma expectativa de que a Cies responda a tudo, que ela seja a própria executiva da política. Mas como? Não tem um instrumento de gestão para fazer isso [...]. (E5).

Para outro entrevistado, a necessidade de submissão dos projetos ao Conselho Estadual, colocada no momento inicial de instituição da Cies, se revelou uma grande dificuldade. O Conselho, ao criar uma comissão para avaliação dos projetos, acabou por atrasar sua aprovação, num processo equivocado e desnecessário.

[...] Mas, com o passar do tempo, com as brigas políticas partidárias, com a aproximação de eleições, nós começamos a não conseguir mais pauta no conselho; eles não aprovavam... Dificultavam a passagem. Enfim, o conselho segurava um ano às vezes um processo [...] Então, esse foi um dos fatores que dificultou muito a execução, e foi um equívoco; não precisava ter acontecido isso. (E6). 


\section{Estratégias para o enfrentamento das dificuldades}

Nessa categoria, um elenco bastante amplo e diversificado de propostas, possibilidades e ações foi apresentado pelos entrevistados. Integram o cardápio propostas de levantamento de atividades já programadas e sua possibilidade de reprogramação; a sensibilização de gestores municipais de saúde no sentido de um maior entendimento acerca da importância da PNEPS e que a mesma integre o rol de compromissos assumidos pelos municípios; a realização de pesquisa avaliativa para verificar o impacto dos cursos nos serviços e se ainda são necessários; e a criação de um departamento de educação em saúde na SES.

[...] outra estratégia que a gente tem caminhado nessa direção é essa pesquisa, ver o que realmente está mudando no serviço, toda essa informação para justamente nessa discussão dos cursos que ainda estão para acontecer se eles são realmente necessários ou não. (E1).

[...] mas eu acho que teria que ter realmente um entendimento, uma sensibilização dos gestores municipais de saúde quanto à importância da política de Educação Permanente, inclusive, que a Educação Permanente faz parte dos termos de compromissos que eles assinam com relação às metas e indicadores dos estados. (E2).

Outro entrevistado sugeriu como estratégias: insistir e tentar convencer o gestor sobre a importância da institucionalização das coordenações regionais; ter estrutura e desenhar os processos de trabalho; definir claramente o papel de cada Cies e como será executado; e estabelecer estratégias para a inclusão de pautas nas CIRs e CIB.

Tentar mais uma vez conversar com o gabinete sobre a possibilidade da institucionalização dessas coordenações, porque aí você cria em cada região um ponto focal, uma pessoa de referência [...] acho que o papel da gente é continuar insistir nessa discussão. (E3).

Ainda para esse mesmo entrevistado, a realização das conferências regionais de saúde foi vista como uma oportunidade de inserção da discussão da EP, ligando-a ao tema da conferência e demonstrando sua contribuição no desenvolvimento das questões levantadas. Outras estratégias levantadas por ele foram aperfeiçoar e articular as ofertas de capacitação, que são pulverizadas e desconexas; aperfeiçoar os cursos existentes, associando projetos de aperfeiçoamento e especialização e criando uma conexão entre eles; integrar conteúdos fragmentados e organizá-los de forma modular em projetos de formação, e inserir esse conjunto de projetos de formação em um programa de qualificação. Por fim, o convencimento dos atores internos e externos a trabalhar nesta lógica também foi reforçado como uma estratégia.

[...] as conferências o tema também central é esse: Análise da situação de saúde. [...] aproveitar essa discussão e dizer [...] Como a Educação Permanente pode contribuir para melhorar esses marcadores de saúde. (E3).

A realização de capacitações, em especial um curso em finanças públicas para instrumentalizar as Cies na execução de recursos, bem como uma proposta para apoiar tecnicamente as Cies, objetivando a construção coletiva dos planos de EP e a facilitação da prestação de contas, foram estratégias levantadas por outro entrevistado.

Corroborando essa proposição, França et al. (2016) identificaram alguns exemplos de limitações do uso desses recursos: a baixa capacidade de gasto pelos estados, associada a recursos carimbados, onde há pouca flexibilidade de utilização, além dos limites impostos pela Lei $\mathrm{n}^{\mathrm{o}}$ 8.666, e questionamentos do Tribunal de Contas. Este conjunto de limites reforça a proposição do entrevistado.

Para outro entrevistado, a estratégia seria 
exigir da gestão maior participação dos atores envolvidos e maior democratização do processo, no qual a coordenação seria eleita pelos próprios membros. Informou ter elaborado e divulgado em congressos, fóruns do conselho, blogs e no site do Cebes um texto crítico à forma de condução do processo.

A gente descobriu [...] uma minuta de uma portaria que já estava pronta e era muito mais para referendar e aí eu fiz até um texto que a gente fez uma militância com ele nos congressos. Foi o congresso da Abrasco no Rio Grande do Sul e lá [...] a gente fez a apresentação dessa crítica a essa portaria e depois eu fiz até um texto e a gente publicou em alguns blogs e que terminou indo também para o site lá do Cebes. (E5).

Outras estratégias elencadas foram: execução de várias ações pela Cies, dentro do que era possível - mesmo que não totalmente dentro do que se defendia como EP; estímulo à Cies e aos municípios para elaborarem projetos; trabalho junto aos gestores no intuito de despertá-los para a política; cobrança de contrapartida do estado para as ações que estavam sendo desenvolvidas; crítica às instituições de ensino, que deveriam ser protagonistas e não cumpriam esse papel; e realização de curso de gestão regionalizada com pesquisa acoplada e estímulo aos gestores para que enviassem relatórios mostrando os avanços alcançados e as experiências exitosas.

[...] quando a gente começou a funcionar a Cies, a gente começou a executar várias coisas, lógico que não dentro de uma política que a gente defende de Educação Permanente, mas dentro do que era possível. Então, a gente começou a estimular tanto as Cies como os municípios que fizessem os projetos [...] [...] seduzindo os gestores que tenham dinheiro, que tenham recursos, para ver se ele despertava para essa política. (E5).

Um encontro nacional das Cies, esta foi uma das estratégias propostas por outro entrevistado. A ideia do encontro surgiu após a realização de uma roda de conversa sobre a comissão, por ocasião da reunião da Rede de Escolas, em junho de 2015. Essa roda não estava programada e foi avaliada como muito produtiva. Para esse depoente, a concepção plural da composição da Cies é vista como uma estratégia de descentralização de poder na comissão, uma vez que dilui o poder da gestão. Ressaltou a necessidade da presença dos movimentos sociais e dos usuários no processo de discussão, afirmando que a reunião desses atores é estratégica, uma vez que oportuniza a discussão entre eles. Assim, acredita que essa composição e esse diálogo entre os atores ajudariam na continuidade da comissão, impedindo seu encerramento.

[...] acho que a concepção de composição das Cies que tem que ser plural é uma das estratégias que favorece que ela não fique fechada, que ela não dê todo poder a gestão, que ela não deixe o controle social, sozinho, né? Quer dizer, os movimentos sociais, os usuários têm que estar ali dentro pra conversar, porque se não a gente tem a gestão fazendo o que acha que tem que fazer, se achando muito legítima. [...]. (E6).

\section{Desafios e perspectivas}

Desafios a serem superados, bem como perspectivas positivas e propostas de trabalho, foram reconhecidos pela maior parte dos entrevistados.

Dentre os desafios, a questão conceitual da EP foi ressaltada por um dos entrevistados no sentido que não seja restrita à qualificação dos profissionais. Para ele, há a necessidade de se entender o que se está chamando de EP para não confundi-la com educação profissional, tradicionalmente associada com curso, sala de aula, certificação, já que a EP vai além. Acredita que a superação dessa confusão conceitual poderia ser alcançada, dentre as alternativas, por meio da produção de materiais, vídeos e estratégias de comunicação, bem como pela recuperação do conhecimento produzido em algumas iniciativas já desenvolvidas. 
[...] hoje o grande desafio da política nacional de Educação Permanente é a gente retomar um pouco essa perspectiva de Educação Permanente, que é uma coisa que não está restrita à qualificação dos profissionais. (E8).

Vários estudos abordam os aspectos que envolvem o conceito de EP, embora todos convirjam para o mesmo núcleo: o de que a EP reconhece a importância e o potencial educativo do processo de trabalho para a sua transformação (BATISTA; GONÇALVES, 2011; CAMPOS, 2006; CAMPOS ET AL., 2006; SARRETA, 2009; LIMA; albuQuerQue, Wenceslau, 2014). Contudo, Campos (2006) destaca que o significado da EP virou uma coisa sagrada, 'santa'. Em virtude disso, tem-se subestimado o papel dos cursos regulares em nome de uma educação na vida e no trabalho, que, apesar de importante, é complementar. $\mathrm{O}$ autor afirma que se terminou avançando pouco na reconstrução e ampliação de projetos para formação de pessoal para o SUS.

$\mathrm{O}$ mesmo entrevistado também destacou a necessidade de se discutir acerca do reconhecimento e contabilização da carga horária utilizada para formação do profissional. Sugere que seja incluída no processo de trabalho desde que acompanhada de uma reflexão e que a experiência seja um dispositivo de aprendizagem, mencionando a necessidade de se pensar outras questões, como a análise do processo de trabalho.

Em geral, os gestores têm visão instrumental e tendem a dificultar a participação dos trabalhadores em processos mais longos de formação (CAMPOS, 2006). Signor et al. (2015) corroboram essa afirmativa. Investigando um serviço de saúde de atendimento misto no qual funciona uma Unidade de Pronto Atendimento (UPA) 24 horas em município do norte do Rio Grande do Sul, os autores constataram não haver incentivo ou estímulo dos gestores municipais para a realização de capacitações da equipe.

Outro entrevistado destacou a importância de se fomentar o trabalho participativo com o envolvimento de todos os atores, cada um ciente da importância de seu papel e da representação de seu segmento. Destacou, também, a necessidade de se implantar as Cies regionais; e de se acompanhar o impacto das ações na qualificação dos serviços, num monitoramento contínuo das ações, além de se promover maior desenvolvimento da área da pesquisa.

[...] a perspectiva é de fomentar mesmo esse trabalho bem participativo, todos os atores envolvidos tenham a ciência da importância do seu papel e da representação do seu seguimento que possa realmente contribuir e que a gente possa também caminhar para a implantação das Cies regionais e que a gente possa fazer esse acompanhamento do impacto da qualificação do serviço, ou seja, que a gente possa trabalhar para que esse monitoramento e essa avaliação seja algo contínuo e não pontual. (E1).

A partir de um encontro nacional, um entrevistado vislumbrou a perspectiva tanto de alavancar a Cies estadual como de ela funcionar como apoiadora das Cies regionais.

A gente está muito esperançosa, a partir desse encontro que a gente teve lá na Escola Técnica do SUS, dessa última oficina, e já a partir dessa reunião que a gente vai realizar agora dia primeiro de setembro de realmente alavancar tanto a Cies estadual como também trabalhar a Cies estadual como órgão apoiador das Cies regionais no sentido de realmente de efetivar a política de Educação Permanente. (E2).

Maior envolvimento das pessoas e realização de rodas de conversa sobre EP para esclarecimento do papel de cada um, da importância do seu comprometimento, participação e da organização do trabalho, foram aspectos levantados por outro entrevistado. Este acredita ser necessário fornecer elementos para que os membros da Cies encontrem alternativas para sensibilizar os gestores de seus municípios para um melhor entendimento da EP, ao mesmo tempo em que considerou a necessidade de sensibilizar 
as instituições formadoras da capital e do interior. Por fim, reforçou a importância de se ter presença e dar visibilidade à EP, de forma a incluí-la na agenda.

[...] vamos começar um trabalho com as rodas de conversas sobre a Educação Permanente [...] Para que as pessoas passem a entender melhor qual é o seu papel, a importância do seu comprometimento, da sua participação, da sua organização do trabalho, como é que elas vão buscar a se organizarem nos seus municípios lá nas suas regiões de saúde para que elas encontrem alternativas de sensibilizar os gestores nessas reuniões das CIR [...] para sensibilizar esse gestor para que ele entenda melhor a importância da Educação Permanente nas ações de serviço, nas ações de saúde no dia a dia. (E3).

Para um dos entrevistados, a execução financeira adquiriu centralidade em todas as reuniões das Cies, sendo necessário o equacionamento dessa questão. Expôs, também, a necessidade de se discutir a micropolítica, uma vez que questões tais como o processo de trabalho, sua rotina, não dependem de recursos, mas do investimento de todos os envolvidos - trabalhadores, docentes, gestores e controle social.

[...] a execução financeira dos recursos que chegam. [...] vira o tema central praticamente de todas as reuniões. [...] a gente sabe que não é a única questão. Só que enquanto não se equacionar, entre aspas, essa reserva financeira que a gente tem aí a gente não vai conseguir discutir a micropolítica. (E4).

As pesquisas de Pierantoni e Garcia (2012) e Ferraz et al. (2013) identificaram que, no que diz respeito à efetivação da PNEPS, a liberação dos recursos e o esclarecimento de dúvidas acerca da gestão financeira são as maiores dificuldades referidas pelos gestores. Para Ferraz et al. (2013), a despeito de as distintas instâncias do SUS terem sido capazes de produzir mecanismos ágeis para o financiamento e contratação de ações e serviços de saúde, o mesmo não se observou nas ações e serviços educacionais.

Stroschein e Zocche (2011) e D'Avila, Assis e Melo (2014) defendem que é preciso o aperfeiçoamento dos processos administrativos e de marcos legais de estados e municípios, os quais devem estar aptos e dispor de meios para a contratação e execução das ações de EP. Aspectos tais como critérios de distribuição de recursos financeiros para implantação e acompanhamento de projetos foram mencionados (PAULINO ET AL., 2012).

O mesmo respondente classificou como fundamental a parceria com as instituições de ensino, embora tenha mencionado que deveriam envolver mais os docentes nos processos para que haja troca de conhecimento e maior participação nos serviços, de forma a não sobrecarregar os preceptores. Reconheceu, contudo, a existência de dificuldades; dentre elas estão o baixo salário dos preceptores e o pequeno número de docentes.

Encarar sua atuação como uma militância; não parar de acreditar; ter uma postura otimista e não desistir; entender que o desafio é longo, instigante e estimulante, bem como acreditar estar fazendo parte de um processo histórico, foram algumas das questões levantadas por outro respondente. Para ele, ter um plano estadual ainda constitui um desafio, e atribui à Escola um papel estratégico na coordenação dos processos de formação no estado, incluindo a residência e os mestrados profissionais.

[...] um desafio ainda, a gente nem tem plano estadual, praticamente não considero plano porque os próprios gestores nunca se preocuparam muito com isso, tornar a política como carro chefe. [...] a gente defende que a escola que assuma essa política, que ela coordene o processo estadual [...] mestrados multiprofissionais e a residência médica [...]. (E5).

No que se refere às instituições de ensino, acredita que precisam ter um papel de maior 
protagonismo no processo de mobilização e agregação e que sua contribuição poderia se dar por meio de debates, publicações, avaliações, dentre outras estratégias. Por fim, ressaltou o valor da realização de pesquisas como esta, que contribuem, dão visibilidade e mostram caminhos.

[...] é um desafio longo, mas é instigante e estimulante, e eu acho que um trabalho como esse que vocês estão fazendo contribui com isso. Porque dá visibilidade e aponta caminhos. (E5).

Para outro respondente, a Cies é uma estratégia que se fortaleceu no processo e não foi desmontada. Contudo, acredita que ela vai passar por um processo de reestruturação, sendo esse um momento de retomada e de reorganização. Devido ao tenso momento pelo qual passa seu estado, manifestou sentimento paradoxal em relação às perspectivas da Cies devido ao momento político vivenciado, i.e., grave greve geral dos servidores, momento de muita instabilidade. Acredita, contudo, que nesse cenário de instabilidade política, econômica e institucional, a Cies vai se reorganizar e avaliar a política de EP como sendo forte. Por fim, acredita que se houver mudança será para melhor.

Perspectivas [...] As piores. Mas eu acho que vai ser muito boa. É paradoxal, isso, né? Mas é, os piores porque a gente está num momento de greve muito grave [...] A situação está muito, muito, muito, muito grave. [...] [...] a gente está vivendo um momento de muita, muita, muita instabilidade. Um momento político de muita instabilidade. E nesse cenário todo de muita instabilidade política, econômica, institucional eu acho que Cies vai se reorganizar. (E6).

\section{Considerações finais}

A EPS tem sido compreendida quanto aos seus pressupostos conceituais e metodológicos como uma estratégia transformadora das práticas de saúde, com grande potencial para o rompimento do paradigma tradicional que orienta os processos de formação dos trabalhadores da saúde. A PNEPS convoca os sujeitos ao quadrilátero da formação - ensino, serviço, gestão e controle social - para refletirem de modo permanente sobre a realidade posta e a encontrar soluções criativas com a superação dos problemas de saúde e, por conseguinte, qualificar as ações no intuito de aumentar a capacidade de resolução e a eficiência do sistema de saúde.

Neste trabalho, foram reconhecidas perspectivas positivas, desafios a serem superados e propostas de trabalho. Contudo, os relatos também mostraram dificuldades, as quais integraram um rol de questões tanto no que se refere a processos internos e inerentes a cada estado como a questões de âmbito mais geral.

Muitos desafios ainda precisam ser superados para que se concebam os projetos de EPS e se consolide a PNEPS; dentre eles, citam-se o planejamento e a implementação da PNEPS em âmbito regional, cuja manutenção precisa se efetivar por meio de gestão participativa e colegiada, exercitando o processo de descentralização e negociação democrática, sustentada nas necessidades locais. Esse processo requer, no entanto, esforços de articulação de parcerias institucionais entre serviço e ensino, educação e trabalho, baseada no diálogo e compartilhada.

Não obstante os desafios e dificuldades que permeiam os processos de implantação e manutenção da EPS, muitas são as contribuições advindas das experiências em curso, que merecem estudos mais aprofundados.

Reforça-se que este estudo não esgota todas as possibilidades. As análises aqui apresentadas devem ser discutidas e divulgadas entre os diversos atores envolvidos no processo para apreciação, validação e construção de alternativas para o campo da educação em saúde, visando ao fortalecimento do SUS. 


\section{Referências}

BATISTA, K. B. C.; GONÇALVES, O. S. J. Formação dos profissionais de saúde para o SUS: significado e cuidado. Saúde Soc., São Paulo, v. 20, n. 4, p. 884-99, 2011.

BRASIL. Portaria GM/MS nº 1.996, de 20 de agosto de 2007. Dispõe sobre as diretrizes para a implementação da Política Nacional de Educação Permanente em Saúde e dá outras providências. Diário Oficial [da] República Federativa do Brasil, Brasília DF, 22 ago. 2007. Disponível em: <http://bvsms.saude.gov.br/bvs/saudelegis/gm/2007/prt1996_20_08_2007.html>. Acesso em: 16 ago. 2017.

BARDIN, L. Análise de conteúdo. 4. ed. Lisboa: Edições $70,2008$.

CAMPOS, F. E. et al. Os desafios atuais para a educação permanente no SUS. Cad. RH Saúde, Brasília, DF, v. 3, n. 1, p. 39-51, 2006.

CAMPOS, G. W. S. Políticas de formação de pessoal para o SUS: reflexões fragmentadas. Cad. $R H$ Saúde, Brasília, DF, v. 3, n. 1, p. 52-6, 2006.

D’AVILA, L. S.; ASSIS, L. N.; MELO, M. B. Adesão ao Programa de Educação Permanente para médicos de família de um estado da Região Sudeste do Brasil. Ciência \&t Saúde Coletiva, Rio de Janeiro, v. 19, n. 2, p. 401-16, 2014.

FRANÇA, T. Análise da Política de Educação Permanente do SUS (PEPS) implementada pelas Secretarias Estaduais de Saúde (SES). Relatório Final. Rio de Janeiro: Uerj, 2016. (v. 2). Disponível em: <http://www.obsnetims.org.br/uploaded/3_2_2016_0_ Vol\%20II_Relatorio_EPSUS_Cnpq_2015.pdf>. Acesso em: 3 jan. 2017.

FRANÇA, T. et al. Política de Educação Permanente em Saúde no Brasil: a contribuição das Comissões Permanentes de Integração Ensino-Serviço. Ciência $\mathcal{E}$ Saúde Coletiva, Rio de Janeiro, v. 22, n. 6, p.1817-1828, 2016.

FERRAZ, F. et al. Gestão de recursos financeiros de educação permanente em saúde: desafio das comissões de integração ensino-serviço. Ciência \& Saúde Coletiva, Rio de Janeiro, v. 18, n. 6, p. 1683- 93, 2013.

KEHRIG, R. T.; SOUZA, E. S; SCATENA, J. H. G. Institucionalidade e governança da regionalização da saúde: o caso da região Sul Mato-Grossense à luz das atas do colegiado de gestão. Saúde em Debate, Rio de Janeiro, v. 39, n. 107, p. 948-961, out./dez. 2015.

LIMA, S. A. V.; ALBUQUERQUE, P. C.; WENCESLAU, L. D. Educação permanente em saúde segundo os profissionais da Gestão de Recife, Pernambuco. Trabalho, Educação e Saúde, Rio de Janeiro, v. 12, n. 2, p. 425-41, 2014.

MACHADO, J. F. F. P. et al. Educação Permanente no cotidiano da Atenção Básica no Mato Grosso do Sul. Saúde em Debate, Rio de Janeiro, v. 39, n. 104, p. 102-113, jan./mar. 2015

PAULINO, V. C. et al. Ações de educação permanente no contexto da Estratégia Saúde da Família. Rev. Enferm. UERJ, Rio de Janeiro, v. 20, n. 3, p. 312-6, 2012.

PIERANTONI, C. R.; GARCIA, A. C. P. A gestão do trabalho e da educação na saúde em secretarias estaduais e municipais de saúde. Divulgação em Saúde para Debate, n. 47, p. 44-54, 2012.

PINTO, I. C. M. et al. . Trabalho e educação na saúde: diálogos entre a produção científica e as políticas de saúde. In: TEIXEIRA, C. F. (Org.). Observatório de análise política em saúde. Salvador: EDUFBA, 2016, p. 431-460.

SANDRI, J. V. A. A comissão de integração ensino e serviço regional: sua trajetória no estado de Santa Catarina. Revista Brasileira de Tecnologias Sociais, Itajaí, v. 3, n. 2, 2016.

SARRETA, F. O. Educação permanente em saúde para os trabalhadores do SUS. São Paulo: Editora Unesp, 2009.

SIGNOR, E. et al. Educação permanente em saúde: 
desafios para a gestão em Saúde Pública. Rev. Enferm. UFSM, Santa Maria, v. 5, n. 1, p. 1-11, 2015.

SILVA, L. A. A. et al. Educação permanente em saúde na ótica de membros das Comissões de Integração Ensino-Serviço. Rev. Enferm. UFSM, Santa Maria, v. 3, n. 2, p. 296-306, 2013 .

STROSCHEIN, K. A.; ZOCCHE, D. A. A. Educação permanente nos serviços de saúde: um estudo sobre as experiências realizadas no Brasil. Trabalho, Educação e Saúde, Rio de Janeiro, v. 9, n. 3, p. 505-19, 2011.
VIANA, A. L. d'Á. Relatório final da pesquisa de Avaliação e Acompanhamento da Política de Educação Permanente em Saúde. São Paulo: USP, 2007.

Recebido para publicação em abril de 2017

Versão final em julho de 2017

Conflito de interesses: inexistente

Suporte financeiro: Conselho Nacional de Desenvolvimento Científico e Tecnológico (CNPq) sob o número de processo 401249/2013-1 